\title{
MIXTURE DISTRIBUTION HYPOTHESIS AND THE IMPACT OF A TOBIN TAX ON EXCHANGE RATE VOLATILITY: A REASSESSMENT
}

\author{
Olivier Damette \\ Université de Lorraine
}

This paper applies smooth transition regressions to incorporate nonlinearity into the impact of trading volume on exchange rate volatility, the so-called mixture distribution hypothesis $(\mathrm{MDH})$. Linking this analysis to the Tobin tax debate, we provide the first empirical corroboration that such a tax may be effective in limiting speculation and reducing exchange rate volatility, especially in turbulent times. Our study points to two main results. First, we show that nonlinearities should be taken into account to explain the MDH. When volatility, spreads, and volume are simultaneously high, the relationship between trading volume and volatility tends to grow stronger and thus the MDH holds in turbulent periods. Second, on the assumption of constant trading volume elasticity, a Tobin tax would have been stabilizing and effective in the 2008 crisis.

Keywords: Tobin Tax, Exchange Rate Volatility, STR Models, Nonlinearity, Mixture Distribution Hypothesis

\section{INTRODUCTION}

The economic downturn following the subprime crisis and the recent sovereign debt crisis has led to renewed interest in a Tobin tax. Such a tax is viewed as a possible way of dampening the deficits of industrialized countries. The European Parliament ${ }^{1}$ has recently approved a proposal to tax financial transactions in eleven European countries, justifying this by the fact that a Tobin tax can generate large revenues. However, the original purpose of the so-called Tobin tax was not to produce revenue for industrialized countries but to stabilize exchange rates.

Indeed, in 1972, during the Janeway Lectures at Princeton, James Tobin suggested putting "some sand in the wheels of international finance" by imposing a tax on all foreign exchange transactions. His proposal aimed first at preserving

\footnotetext{
I would like to thank G. Galati, B.J. Park, D. Rime, B. Koebel, Ph. Frouté, J. Lopez, G. Duchêne, and F. Jawadi for their helpful discussions. I am also grateful to Ralf Brueggemann, who accepted to share his Ox code concerning STR-GMM estimates. I thank Olsen Financial Studies for giving me access to their data, and BETA-CNRS UMR7522 and ERUDITE for financial support. Finally, I am grateful to two anonymous referees and an associate editor for their very valuable comments on a previous version of this paper. Address correspondence to: Olivier Damette, Faculté de Droit et de Sciences Economiques, Université de Lorraine, BETA-CNRS, and LEF-INRA, 13 place Carnot, 54035 Nancy Cedex, France; e-mail: olivier.damette@univ-lorraine.fr.
} 
and strengthening the autonomy of national monetary policies in the early 1970s, following the decision by the U.S. government to come off the gold standard and introduce floating exchange rates. As Tobin wrote, "monetary policy becomes, under floating rates, exchange rate policy" (1978, p. 156). The second aim was to reduce foreign exchange rate and financial volatility. Tobin's underlying thinking [see Tobin $(1974,1978,1984,1996)$ and Eichengreen et al. (1995)] was that short-term round-trip transactions (for instance, speculative transactions) are more destabilizing than long-term transactions. This idea had first been put forward by Keynes (1936). The notion of harmful volatility created by speculative trading contrasts with the position taken by Friedman (1953), who argued that speculation is in general not destabilizing but, on the contrary, helps stabilize prices. Friedman believed that buying low and selling high is stabilizing and profitable whereas buying high and selling low is destabilizing and unprofitable, and that the latter strategy would thus be driven out of the market. Tobin suggested that a tax would reduce volatility by discouraging short-term transactions (thereby curbing destabilizing speculative trading) to a greater extent than long-term transactions (and investments) and would thus crowd out speculators from foreign exchange markets (Forex hereafter) in favor of long-term investors.

However, this argument has been challenged by both proponents and opponents of the tax. ${ }^{2}$ There are two main objections to it. First, not all short-term transactions are speculative, but instead they may be a result of the "hot potato" phenomenon. Consequently the large daily turnover of Forex [\$5.3 trillion, BIS (2013)] would reflect not only speculative behavior but also liquidity and risk-sharing behavior. Second, the Tobin tax is an indiscriminate tax and would penalize not only destabilizing transactions but also transactions that provide liquidity and information. Therefore, by crowding out short-term transactions, a tax would be counterproductive and would increase volatility.

There are a wide range of theoretical studies with different frameworks and assumptions providing different results [see McCulloch and Pacillo (2011)]. It emerges from the Tobin tax literature that the main group of theoretical works is based on heterogeneous agent models, ${ }^{3}$ with a view to demonstrating that a tax could reduce the destabilizing part of trading volume. The seminal work of Frankel (1996) explained the rationale of a Tobin tax: if a tax was instituted, it would reduce exchange rate volatility by decreasing short-term transactions. Palley (1999) assumed that there were two groups of risk-neutral traders, fundamentalists and speculators. Although a Tobin tax would hit both kinds of traders, speculators would be affected more, as a result of their higher trading frequency. Thus, a tax would increase market efficiency. More recently, Shi and Xu (2009) go further by modeling the microeconomic behavior of risk-adverse heterogeneous traders in a paper closely related to Jeanne and Rose's (2002) contribution. They showed that a tax does not necessarily lead to a decrease in the relative noise component and is ineffective in reducing volatility.

Another series of studies have attempted to examine the impact of a Tobin $\operatorname{tax}^{4}$ within the framework of a simulation model of heterogeneous interacting agents. 
Using a model with chartists and fundamentalists, Westerhoff (2003) found that the tax may crowd out chartists and thus reduce exchange rate volatility, but pointed to a moderate tax level. Westerhoff and Dieci (2006) investigated the case of a global tax: if regulators impose a tax on all markets, speculation is dampened and the markets are thus less volatile. More recently, Pellizzari and Westerhoff (2009) showed that the effectiveness of a Tobin tax depends on the market microstructure. For dealership markets, a transaction tax may reduce volatility by crowding out speculative transactions, whereas, in limit order book markets, the reduction in liquidity as a result of a tax amplifies the average price impact of a given order

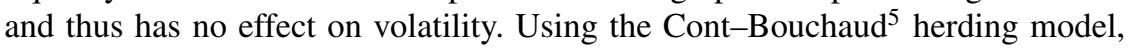
Ehrenstein et al. (2005) concluded that reducing liquidity is likely to increase the price responsiveness of a given transaction, and showed that a Tobin tax would reduce volatility as long as the market's price adjustments did not depend too strongly on liquidity. Using a similar approach with four kinds of agents and two markets, Mannaro et al. (2008) came up with findings conflicting with those of Ehrenstein et al. (2005) and of Westerhoff and Dieci (2006): the taxed market then becomes more volatile than the untaxed one.

The effect of the tax on volatility was also experimented with and several findings were retained. Bianconi et al. (2009) used minority games to show that the effect of a tax would be much stronger in a thin market than in a liquid market. Bloomfield et al. (2009) did not directly assess the impact of a Tobin tax on volatility, but instead used a controlled laboratory experiment. They show that a transaction tax leads to less noise trading and at best has a weak effect on the informational efficiency of prices. Hanke et al. (2010) considered two distinct markets and then introduced a transaction tax into one or both markets. The authors also checked whether tax effects are persistent or not. In the case of a unilateral tax, volatility in the taxed market may decrease or increase depending on the market size, whereas volatility in the untaxed market is reduced because of an increase in liquidity. On the other hand, if a tax is introduced simultaneously in both markets, price volatility and market efficiency remain unchanged.

Finally, the econometric literature is relatively scarce and incomplete. Aliber et al. (2003) constructed time series of future prices traded on the Chicago Mercantile Exchange and showed that transaction costs and volatility are positively correlated on a 1977-1999 sample (except for the German mark). However, they used aggregated futures data, whereas Hartmann (1998a, 1998b) has shown that there is no link between spots and futures on the foreign exchange market. In addition, the choice of contracts from a centralized market as a proxy for the whole market may lead to the omission of variable issues. Second, as emphasized by Werner (2003), the authors interpret their results as evidence that changes in transactions costs cause reductions in volatility, but do not take into account the causality from volatility on spreads and trading volume. Lanne and Vesala (2010), using a high-frequency data set for the Deutsche mark-dollar and yen-dollar exchange rates from 1 October 1992 to 30 September 1993, found a similar result: transactions costs and volatility are positively correlated and thus a Tobin tax 
would be counterproductive by increasing existing costs. The study period does not, however, incorporate recent Forex dynamics.

In this paper, in line with the previous theoretical work, we seek to assess empirically the impact of a Tobin tax on volatility. We try to see whether a reduced volume of transactions would have a destabilizing or a stabilizing effect. To this end, we examine two empirical relationships. On one hand, we look at the influence of a tax on trading volume on the assumption that the tax would increase spreads. On the other hand, we assess the relationship between trading volume and Forex volatility given the expected decrease in trading volume subsequent to the tax. The rationale for examining the relationship between trading volume and volatility comes from mixture distribution hypothesis (MDH) studies, i.e., the positive relationship between volume and volatility. This literature stipulates that price volatility and trading volume dynamics are both coordinated by the same information arrival rate. This question is initially not connected with our research problem, but by evaluating the relationship between trading volume and volatility, we can derive some policy recommendations concerning the functioning modalities of a Tobin tax. Because the tax will necessarily lead to a reduction in trading volume, if we can assess the impact of the volume on volatility, we will then shed some light on the Tobin tax debate in regard to its impact on exchange rate volatility.

Accordingly, our paper makes several contributions. First, we propose to apply the MDH literature to the Tobin tax literature. Second, we investigate this question in a nonlinear framework to capture further asymmetry in our relationships. In particular, unlike previous studies related to the $\mathrm{MDH}$, we made use of the switching regime hypothesis in Forex. ${ }^{6}$ The latter is particularly appropriate to apprehend further heterogeneity of the trading behaviors of traders.

In the present study, we overcome previous linear estimates [Aliber et al. (2003) and Lanne and Vesala (2010)] by allowing for the possibility of nonlinearities in the volume-volatility relationship, consistent with the theoretical work of Jeanne and Rose (2002), Haberer (2004) and Shi and Xu (2009), among others. To this end, we applied a Smooth Transition Regression model (STR). Is this effect uniformly distributed across the different Forex regimes (high appreciation of the euro, low trading volume, the financial crisis, etc.)? What policy recommendations can be derived as a consequence?

The paper derives two important results. First, we show that the MDH depends on the level of the volume traded and on holds in both normal and turbulent times. In addition, we find evidence of an increasing mixture distribution in turbulent times with high volume and volatility, as in the crisis of autumn 2008. The paper thus challenges the MDH literature based only on linear frameworks. Second, our results enable us to assess the stabilizing effect of a Tobin tax on exchange rate volatility. A Tobin tax could decrease volatility by crowding out noise traders, chartists, and speculators, as proposed by advocates of the tax. This effect would be more pronounced in turbulent periods than in normal times. A Tobin tax would thus be more effective in turbulent periods, when the number of speculators is 
very high. For example, a Tobin tax would have been stabilizing in the 2008 crisis, when spreads, volume, and volatility were all at high levels.

The paper is structured as follows. Section 2 deals with the relationship between trading volume and transaction costs. Section 3 explains the nonlinear MDH. The policy implications of our results with regard to introducing a Tobin tax on Forex transactions are discussed in Section 4. Finally, Section 5 concludes.

\section{ESTIMATION OF CURRENCY TRANSACTION TAX ELASTICITY}

To begin with, we assess how trading volume would be reduced by a Tobin tax. It is possible to directly read the impact of a Tobin tax-equivalent to an increase in the spread-on trading volume through the following model:

$$
\ln (\text { volume })_{t}=\beta_{1}+\beta_{2} \ln (\text { spread })_{t}+\beta_{3} \ln (\text { volume })_{t-k}+\beta_{4} \text { volatility }_{t}+\varepsilon_{t} \text {. }
$$

In (1), both volume and spread are expressed in logarithmic form to obtain the coefficient $\beta_{2}$ directly as an elasticity. Note that lagged volume terms are included to take into account further trading volume inertia.

We used daily data from Olsen Financial Technologies consisting of the eurodollar exchange rate quotations from 1 January 2006 until 31 December 2010 (1,300 observations). For comparison, we also use euro-yen and dollar-pound data. Spreads are computed using median Bid and Ask series and are proxies of transaction costs. We compute the relative returns as percentage differences of the averages of the logarithmic median ${ }^{7}$ bid and ask prices and then derive a measure of the daily realized variance by summing squared returns. Thus the volatility can be derived as volatility ${ }_{t}=\sum_{t}^{T}\left[\log \left(R_{t} / R_{t-1}\right)\right]^{2}$, where $R$ are the relative returns of the exchange rates.

Because the current volume of transactions for foreign exchange markets is not readily available (the Forex is decentralized), proxies are needed. The most common choices in the literature ${ }^{8}$ are the quoting frequency and the number of contracts transacted. In our paper, as for example in Bauwens et al. (2005) and Lanne and Vesala (2010), we use the quoting frequency and more specifically a tick-by-tick variable.

We first estimate equation (1) by OLS (see Table 1) and find a smaller elasticity than indicated in the literature. Our elasticity amounts to -0.06 , whereas Bismans and Damette (2008) get -0.33 and -0.61 , using SURE (seemingly unrelated regression) and cointegration techniques, respectively. ${ }^{9}$ Note that all the variables are stationary ${ }^{10}$ and so we are not exposed to the "spurious regression" issue identified by Yule and outlined by Phillips (1986). In addition, the first-, fourth-, and fifth-order lagged values of the dependent variable are needed to take serial autocorrelation into account. ${ }^{11}$ Robust standards errors are corrected for heteroskedasticity (the Breush-Pagan test was used to test this issue).

The divergence between our results and the previous studies could be explained by the fact that our regressions are based on daily data and on a four-year sample, 
TABLE 1. OLS estimation

\begin{tabular}{|c|c|c|c|c|}
\hline & \multicolumn{2}{|c|}{ 2008-2010 } & \multicolumn{2}{|c|}{ 2006-2010 } \\
\hline & Coefficient & $t$-stat & Coefficient & $t$-stat \\
\hline Intercept & 1.12 & 2.74 & 0.36 & 1.68 \\
\hline Spread & -0.05 & -1.96 & -0.06 & -2.75 \\
\hline Volatility & 0.01 & 3.93 & 0.06 & 6.47 \\
\hline Volume $(-1)$ & 0.67 & 15.47 & 0.59 & 10.54 \\
\hline Volume $(-2)$ & -0.09 & -1.73 & - & - \\
\hline Volume $(-3)$ & 0.07 & 1.31 & - & - \\
\hline Volume $(-4)$ & 0.07 & 1.35 & 0.17 & 3.23 \\
\hline Volume $(-5)$ & 0.16 & 3.58 & 0.17 & 4.42 \\
\hline \multicolumn{3}{|c|}{$R^{2}=0.66$} & \multicolumn{2}{|c|}{$R^{2}=0.86$} \\
\hline \multicolumn{3}{|c|}{$T=508$} & \multicolumn{2}{|c|}{$T=1,288$} \\
\hline \multicolumn{3}{|c|}{$\begin{array}{c}\text { Autocorrelation LM } \\
\text { test }=0.520(0.77)\end{array}$} & \multicolumn{2}{|c|}{$\begin{array}{c}\text { Autocorrelation LM } \\
\text { test }=1.464(0.23)\end{array}$} \\
\hline
\end{tabular}

Note: Newey-West standard deviations and covariance correction are used (lag truncation equal to 7 on the 2006-2010 sample). We use the Breusch-Godfrey LM test (with an AR(2) specification) because the Durbin-Watson test is not valid if there are lagged values of the dependent variable on the right-hand side of the estimated equation.

whereas Bismans and Damette (2008) used intraday data for two days in November 2004 only. We think it likely that the previous estimates capture more microstructural effects than our new estimates, and this increases the magnitude of the spread effect. Moreover, the estimate in Table 1 does not take into account the probable endogeneity of the spread. Indeed, some studies [see, for instance, Demos and Goodhart (1996)] have emphasized the existence of two-way causality between volatility and spread, giving rise to an endogeneity problem that must be taken into account to evaluate without bias the relationship between volume and volatility in the Forex. Although GMM (generalized method of moments) estimators provide an interesting alternative to this problem [see Hartmann (1999), for instance], it is nonetheless the case that it is difficult to acquire the right instruments.

To address those issues, we estimate the following simultaneous dynamic equations model ${ }^{12}$ in line with Demos and Goodhart (1996) ${ }^{13}$ with $k \geq 1$ :

$$
\left\{\begin{array}{l}
\ln (\text { volume })_{t}=\beta_{1}+\beta_{2} \ln (\text { spread })_{t}+\beta_{3} \ln (\text { volume })_{t-k}+\beta_{4} \ln (\text { volatility })_{t}+\varepsilon_{1 t} \\
\ln (\text { spread })_{t}=\beta_{5}+\beta_{6} \ln (\text { volume })_{t}+\beta_{7} \ln (\text { volatility })_{t}+\beta_{8} \ln (\operatorname{Spread})_{t-k}+\varepsilon_{2 t}
\end{array}\right.
$$

The first equation is our equation of interest and is similar to (1). It captures the elasticity of the volume with respect to the spread, whereas the second equation 
TABLE 2. GMM-3SLS estimation

\begin{tabular}{lrrlrr}
\hline $\begin{array}{l}\text { Equation (1) } \\
\text { volume }\end{array}$ & Coefficient & $z$-stat & $\begin{array}{c}\text { Equation (2) } \\
\text { spread }\end{array}$ & Coefficient & $z$-stat \\
\hline Intercept & -0.35 & -0.65 & Intercept & -1.04 & -1.34 \\
Spread & -0.15 & -1.72 & Volume & -0.03 & -0.84 \\
Volatility & 0.03 & 0.94 & Spread(-1) & 0.83 & 6.69 \\
Volume (-1) & 0.82 & 6.77 & Volatility & 0.02 & 0.50 \\
Volume (-4) & -0.46 & -2.80 & & & \\
Volume (-5) & 0.55 & 3.54 & & \\
\multicolumn{7}{c}{$T=1,250$ Hansen's $J$ chi $^{2}(16)=13.278(p=0.652)$} \\
\end{tabular}

Note: The set of instruments includes constant and lagged values of the explanatory variables in the different equations: spread $(-2)$ to spread $(-5)$, volatility $(-1)$ to volatility $(-4)$, volume $(-6)$. Different sets of efficient (in the sense of not weak) instruments were used to check the robustness of the estimation. The coefficient of elasticity always lies between -0.15 and -0.25 . Note that 3SLS regressions lead to a very similar elasticity: -0.19 .

focuses on the effect of the trading volume on the spread in line, at least partially, with Hartmann's (1998a, 1998b) and Galati's (2000) studies. Because we assume a nonzero correlation between errors $\varepsilon_{1 t}$ and $\varepsilon_{2 t}$, a 3SLS (three-stage least squares) estimator is better than the individual equation methods (2SLS, LIML, etc.) if the model is correctly specified. ${ }^{14}$

Because diagnostic tests reveal the presence of heteroskedasticity in the system (especially in the first equation), we compute the GMM-3SLS (generalized method of moments - three-stage least squares) estimator. Indeed, unlike the standard 3SLS method, which is a restricted version of the simultaneous equation GMM model, the GMM-3SLS estimator allows for heteroskedasticity in addition to cross correlation. It is, moreover, consistent and efficient without any assumptions about the functional form of the error terms.

The GMM-3SLS method combines a first estimation with instrumental variables in keeping with 2SLS (two-stage least squares) to obtain consistent estimators and a second estimation by GMM to address the problem of correlated error terms [see Zellner and Theil (1962)] and heteroskedasticity using the efficient weighting matrix. Overall, we follow a three-step method. The first two steps involve estimating each equation of the system individually by 2SLS and the third involves estimating the previous estimated equations by GMM. The results of the GMM-3SLS estimations are presented in Table 2. Note also that the $J$ test of overidentifying restrictions is conducted to check the identification of the model.

Table 2 proves that higher spreads would reduce the trading volume significantly. It shows that the elasticity is higher in 3SLS-GMM than in the previous OLS estimates (now -0.15). Furthermore, note that all the lagged volume coefficients are significant at the $10 \%$ level and that the impact of volatility on volume is no longer statistically significant. 


\section{TRADING VOLUME AND VOLATILITY: A NONLINEAR APPROACH}

We now focus on how a decreasing volume following the introduction of the Tobin tax would lead to a decrease in exchange rate volatility. Indeed, a Tobin tax may drive out stabilizing transactions instead of destabilizing ones and thus increase volatility. In addition, the excess demand may have a stronger price impact, such that volatility increases. To study the impact of volume on volatility, our analysis is based on the mixture distribution hypothesis (MDH) literature and STR methods.

\subsection{Methodology}

Using the data set previously detailed, we consider the following model:

$$
\text { volatility }_{t}=\beta_{1}+\beta_{2} \text { volume }_{t}+\beta_{3} \text { volatility }_{t-k}+\varepsilon_{3 t}, t=1, \ldots, 1,300 .
$$

In line with the MDH literature, ${ }^{15}$ we thus expect a positive sign for the $\beta_{2}$ coefficient. However, in our view, threshold and nonlinear effects have been neglected by existing empirical studies. Indeed, theoretical studies such as Jeanne and Rose (2002) and Haberer (2004) have proven analytically the existence of a U-shaped relationship between trading volume and volatility.

As a consequence, mixture distribution may occur only above (or below) certain levels of volume activity (and liquidity), and thus the impact of a Tobin tax on volatility will be different. To empirically assess this phenomenon, we use a logistic smooth transition regression (LSTR) model initially developed by Bacon and Watts (1971) and more recently used by Teräsvirta (1994, 1998), Franses and van Dijk (2000), and van Dijk, Teräsvirta and Franses (2002).

According to the STR model, equation (3) can be rewritten as

$$
\text { volatility }_{t}=\beta_{1} z_{t}+\beta_{2} z_{t} \cdot G\left(\gamma, c, s_{t}\right)+u_{t} \quad z_{t}=\left(w_{t}^{\prime}, x_{t}^{\prime}\right)^{\prime} t=1, \ldots, 1,300,
$$

where $w_{t}^{\prime}=\left(1 \text {, volatility } y_{t-1}, \ldots \text {, volatility } y_{t-p}\right)^{\prime}$ denotes the vector of lagged values of the endogenous variable, volatility, and $x_{t}^{\prime}=\left(\text { volume }_{t}\right)^{\prime}$ is a vector of values of the exogenous variable, trading volume. $\beta_{1}$ and $\beta_{2}$ are parameter vectors and the error term is defined as an i.i.d. process: $u_{t} \sim \operatorname{iid}\left(0, \sigma^{2}\right)$. As previously explained, it is assumed that the trading volume is exogenous in (4). This assumption is needed for consistency of the conditional maximum likelihood estimator of the nonlinear models. The results of Table 2 are in accordance with this assumption, because coefficient $\beta_{6}$ is not significant. Note, in addition, that previous studies on MDH assume weak exogeneity of trading volume.

$G$ is the transition function, a bounded function of the continuous transition variable $s_{t}, \gamma$ is a smoothness parameter, and $c=\left(c_{1}, \ldots c_{K}\right)^{\prime}$ is a vector of location parameters with $c_{1} \leq \ldots \leq c_{K}$. The transition from one regime to another is then smooth, given the values of the slope parameter and the location parameters. The transition function is usually a stochastic variable and an element of the vector $z_{t}=\left(w_{t}^{\prime}, x_{t}^{\prime}\right)$. We assumed that the transition function is a general 
logistic function:

$$
G\left(\gamma, c, s_{t}\right)=\left(1+\exp \left\{-\gamma \prod_{k=1}^{K}\left(s_{t}-c_{k}\right)\right\}\right)^{-1} \text { with } \gamma>0
$$

Note that $K=1$ (the LSTR model becomes the LSTR1 model) and $K=2$ (the LSTR model becomes the LSTR2 model) are the most common choices. In the first case, the parameters change monotonically and smoothly (not instantly when the transition variable surpasses its threshold value) from $\beta_{1}$ to $\beta_{1}+\beta_{2}$, whereas in the second case, they change symmetrically around a midpoint corresponding to the minimum value of the logistic function. The LSTR1 model is thus useful to characterize two different regimes, for instance the dynamics of behavior in expansions and in recessions. On the other hand, the LSTR2 model is able to model situations where the behavior of a given process is similar at both small and large values of the transition function and different in the middle. When $\gamma \rightarrow \infty$, the LSTR2 model approaches the switching regression model with three regimes in which the outer regimes are identical and the midregime is different from the other two [Teräsvirta (2004)].

First, we test $s_{t}=$ volume $_{t-1}$, i.e., whether the transition variable is the firstorder lagged trading volume. Our thinking is based on the recent simulation studies by Pellizzari and Westerhoff (2009) and Bianconi et al. (2009) and also on the recent experimental study by Hanke et al. (2010), who find evidence that the Tobin tax influence depends on market size, and on previous theoretical results in Jeanne and Rose (2002), Westerhoff and Dieci (2006), and Shi and Xu (2009), who find that volatility is related to liquidity and trading volume.

Second, we also tested lagged volatility as a transition variable: $s_{t}=$ volatility $_{t-1}$. The thinking behind this assumption is that the relationship between volume and volatility may be different in normal periods and in turbulent periods, ${ }^{16}$ as shown by Galati (2000) for emerging markets by carrying out rolling regressions. ${ }^{17}$

To detect nonlinear patterns, we carry out the LM-linearity test discussed in Teräsvirta $(1994,1998)$. In the same way as in other nonlinear models, ${ }^{18}$ the STR model is only identified under the alternative hypothesis of nonlinearity. This identification problem can be solved by approximating the transition function by a third-order Taylor expansion under the null hypothesis that $\gamma=0$ (in this case, the transition function $G$ tends to $1 / 2$ ). We then use the $F$-version of the test in this paper. If the null hypothesis is rejected (low p-values) for many transition variables, there are several transition candidates and thus the model is clearly nonlinear. When linearity has been rejected, we then need to choose the type of STR model: $K=1$ and $K=2$ lead to the LSTR1 and LSTR2 models, respectively [see Teräsvirta (2004)].

The results of the linearity tests are shown in Table 3. Note that, to save space, only the results of the preferred specification are reported. ${ }^{19}$ The associated 
TABLE 3. Linearity tests ( $p$-values) for the euro-dollar currency pair

\begin{tabular}{lccccr}
\hline$s_{t}$ & $\mathrm{~F}$ & $\mathrm{~F} 4$ & $\mathrm{~F} 3$ & $\mathrm{~F} 2$ & Model \\
\hline volume $_{t-1}$ & $3.1704 \times 10^{-10}$ & $1.3024 \times 10^{-3}$ & $2.3887 \times 10^{-4}$ & $8.2675 \times 10^{-7}$ & LSTR1 \\
volatility $_{t-1}$ & $6.2479 \times 10^{-25}$ & $7.1175 \times 10^{-4}$ & $1.5975 \times 10^{-1}$ & $2.465224 \times 10^{-24}$ & LSTR1 \\
\hline
\end{tabular}

$p$-values are clearly very small and suggest STR-type nonlinearities when lagged volume and volatility are used as transition variables. The previously described test strategy suggests estimating LSTR1 models.

\subsection{The Euro-Dollar Case}

Given the conclusions of the linearity and specification tests, we estimate the corresponding LSTR1 models $(p, q)$ on the euro-dollar currency pair with $p$ and $q$ respectively denoting the lag lengths of the endogenous and exogenous variables. Note that the stationarity condition is satisfied because all variables are $I(0)$. Under the assumption of exogenous covariates, the method used is nonlinear least squares estimation, or, under the assumption of normally distributed errors, maximum likelihood. As explained by Terävirsta (2004), the BFGS (BroydenFletcher-Goldfarb-Shanno) algorithm can be used with the numerical derivatives of the log-likelihood function. ${ }^{20}$ It is important to choose good starting values for the transition parameters $\gamma$ and $c_{1}$ in the case of a LSTR1 model. After constructing a grid, we can estimate parameters $\beta_{1}$ and $\beta_{2}$ conditionally on the transition parameters and select the estimates minimizing the sum of squared residuals.

Regarding Table 4, we found evidence of some nonlinearity in the mixture distribution. Our results show that the $\mathrm{MDH}$ is stronger in periods of relatively high trading volume and high volatility. More precisely, when the lagged trading volume exceeds an estimated threshold value of about 12.32 [column (2), Table 4], the nonlinear part of the model comes into play and the semielasticity of the trading volume increases smoothly from 0.399 to $1.54(0.399+1.141)$, indicating an increased role of information in the volatility dynamics [model (2)]. In a similar manner, when the lagged volatility surpasses a threshold value of 2.37 [column (3), Table 4], the link between volatility and volume is stronger. In STR models, the change between linear and nonlinear regimes does not occur instantly, given the transition speed parameter $(\gamma)$. The transition starts when the transition variable surpasses its threshold (see Figure 1), and once the transition is complete, the nonlinear regime applies fully (see Figures 2 and 3). The following formula depicts the transition path:

$$
\left(\beta_{0}+\beta_{1, t}\right)(1+\exp \{-\gamma(x) / \mathrm{sd}\})^{-1},
$$

where sd is the standard deviation of the transition variable and $x$ is the difference between the transition variable and the threshold value. 
TABLE 4. Conditional ML estimates for LSTR model

(2) concerning the euro-dollar currency pair with lagged volume as a transition variable, 2006-2010

\begin{tabular}{|c|c|c|c|}
\hline $\begin{array}{l}\text { Model } \\
s_{t}\end{array}$ & $\begin{array}{c}(1) \\
\text { LSTR1 } \\
\text { Volume }_{t-1}\end{array}$ & $\begin{array}{c}(2) \\
\text { LSTR1 } \\
\text { Volume }_{t-1} \\
\end{array}$ & $\begin{array}{c}\text { (3) } \\
\text { LSTR1 } \\
\text { Volatility }_{t-1}\end{array}$ \\
\hline \multicolumn{4}{|c|}{ Linear part } \\
\hline Constant & $\begin{array}{l}-4.213^{* * *} \\
(-6.38)\end{array}$ & $\begin{array}{l}-4.350^{* * *} \\
(-5.96)\end{array}$ & $\begin{array}{l}-3.396^{* * *} \\
(-8.60)\end{array}$ \\
\hline Volume & $\begin{array}{l}0.389^{* * *} \\
(6.72)\end{array}$ & $\begin{array}{l}0.399^{* * *} \\
(6.17)\end{array}$ & $\begin{array}{l}0.314^{* * *} \\
(9.38)\end{array}$ \\
\hline Volatility $_{t-1}$ & - & $\begin{array}{l}0.156^{* * *} \\
(3.06)\end{array}$ & - \\
\hline \multicolumn{3}{|c|}{ Nonlinear part } & - \\
\hline Constant & $\begin{array}{l}-21.189^{* * *} \\
(-4.79)\end{array}$ & $\begin{array}{l}-14.695^{\text {*** }} \\
(-3.75)\end{array}$ & $\begin{array}{l}-29.12^{* * *} \\
(-7.59)\end{array}$ \\
\hline Volume & $\begin{array}{l}1.687^{* *} \\
(4.806)\end{array}$ & $\begin{array}{l}1.141^{\text {*** }} \\
(-3.75)\end{array}$ & $\begin{array}{l}2.46^{* * *} \\
(7.92)\end{array}$ \\
\hline Volatility $_{t-1}$ & - & $\begin{array}{c}0.050 \\
(0.638)\end{array}$ & - \\
\hline Volatility $_{t-2}$ & - & $\begin{array}{l}0.283 \\
(3.50)\end{array}$ & - \\
\hline$\gamma / \hat{\sigma}_{s}$ & $\begin{array}{l}5.35 \\
(2.06)\end{array}$ & $\begin{array}{l}4.03 \\
(2.30)\end{array}$ & $\begin{array}{l}17.02 \\
(2.20)\end{array}$ \\
\hline$c_{1}$ & 12.33 & 12.32 & 2.37 \\
\hline R2 & 0.13 & 0.20 & 0.20 \\
\hline
\end{tabular}

Note: $t$-stats are in parentheses.

To go further, we try to place the linear and nonlinear parts outlined by the regression in historical perspective. Our analysis detects four main periods:

- An initial period corresponding to low trading volume and volatility levels (only the linear part applies) from January 2006 to September 2008. The impact of volume on volatility is low. Indeed, the values of the transition variables - volume and volatility — are below their threshold over this period (see the left-hand sides of Figures 1 and 4), the values of the transition functions (see Figure 5) and the probability of the transition function (Figure 3) are extremely low, and the nonlinear part of the fitted LSTR model is flat (see the right panel in Figure 6).

- A second period from September 2008 (corresponding to 15 September 2008 , about the 705 th observation), with very high trading volume, volatility, and a strengthening of the volatility/volume relationship; see the peaks in the middle of Figures 3, 5, and 6. 


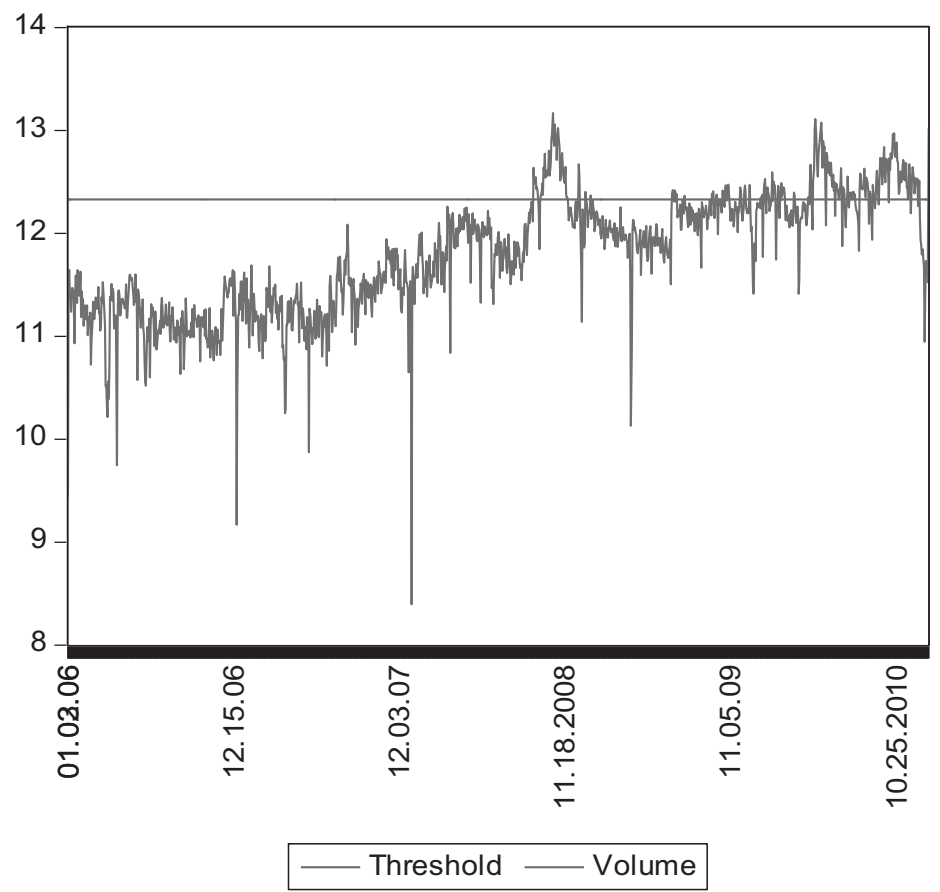

FIGURE 1. Euro-dollar trading volume dynamics and threshold value. Threshold refers to the threshold value of volatility estimated by the STR model [Table 4, column (2)].

- A third period from early 2009 to spring 2010, corresponding to a slowdown in Forex, with a smaller trading volume and a narrower volatility/volume correlation. Indeed, the linear part predominates over the nonlinear part (see Figure 6) and the values of the transition variables decrease sharply (Figures 3 and 5).

- A final period, from the end of March 2010 to the end of December 2010, in which the trading volume was repeatedly above its estimated threshold value (see the increasing values on the right-hand sides of Figures 2, 3, and 5). The dynamics of the trading volume was, however, not monotonic over this period and the nonlinear part applies only for the lagged trading volume as a transition variable.

Consequently, an interesting finding is that we do not corroborate the results obtained by Galati (2000), who found the correlation between trading volumes and volatility to be positive during "normal" times but negative when volatility increased sharply, implying that the MDH holds only under normal market conditions. In contrast, we find evidence of increasing mixture distribution in turbulent times, as in the autumn of 2008 at the peak of the financial crisis caused by the sub-prime crisis and intensified by the bankruptcy of Lehman Brothers. 


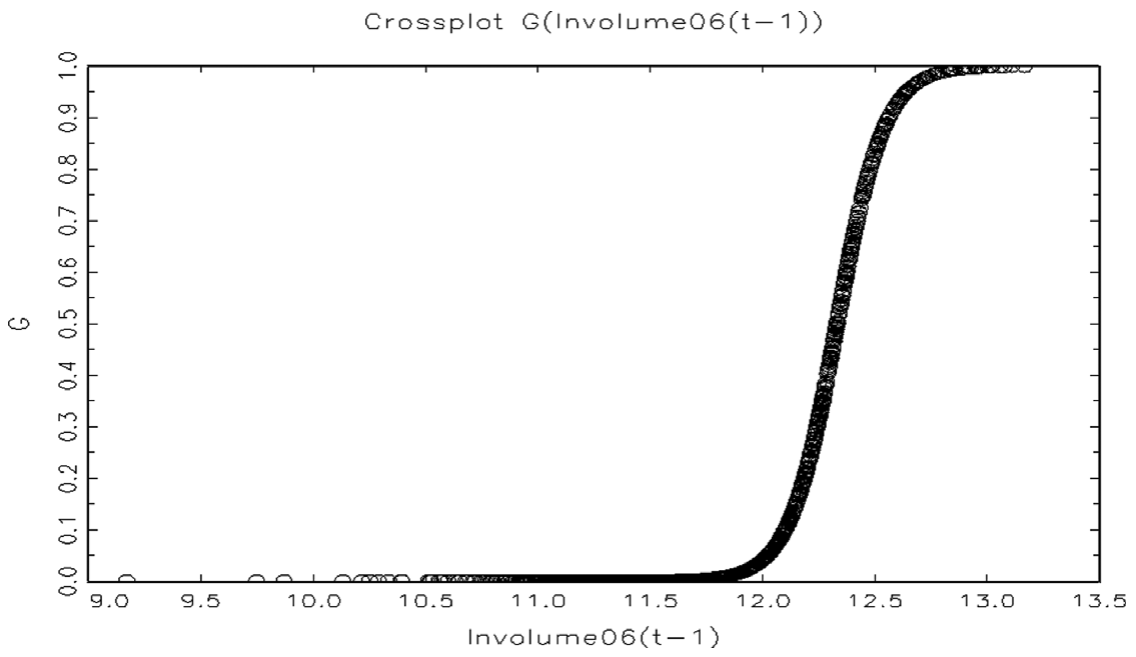

FIGURE 2. Estimated logistic transition function with the lagged trading volume as a transition variable (euro-dollar). Values of the transition function are plotted against the transition variable.

Plot of Time Series $4-1300.0, T=1297$

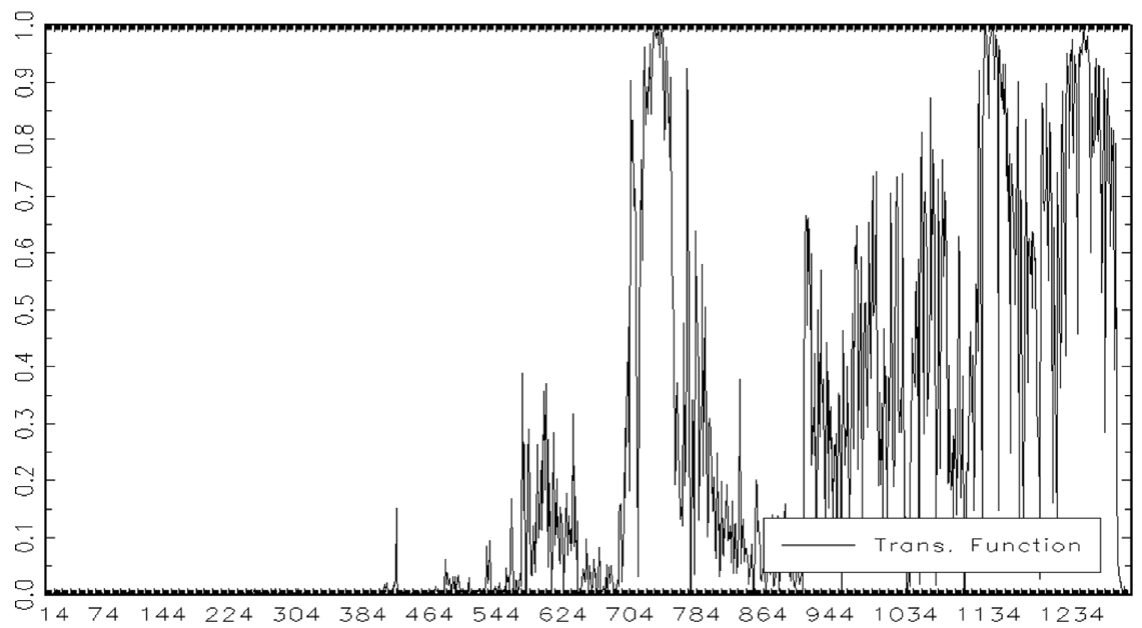

FIGURE 3. Transition function of estimated LSTR1 with the lagged trading volume as a transition variable (euro-dollar): estimated transition probabilities. Values of the transition function are plotted against time.

These findings need to be qualified, however. Our results do not mean that the mixture distribution increases only in crisis periods. Indeed, looking at the historical data, we see that the first period of nonlinearity detected by the model (autumn 2008 to January 2009) exhibits simultaneously high volatility, spreads, 


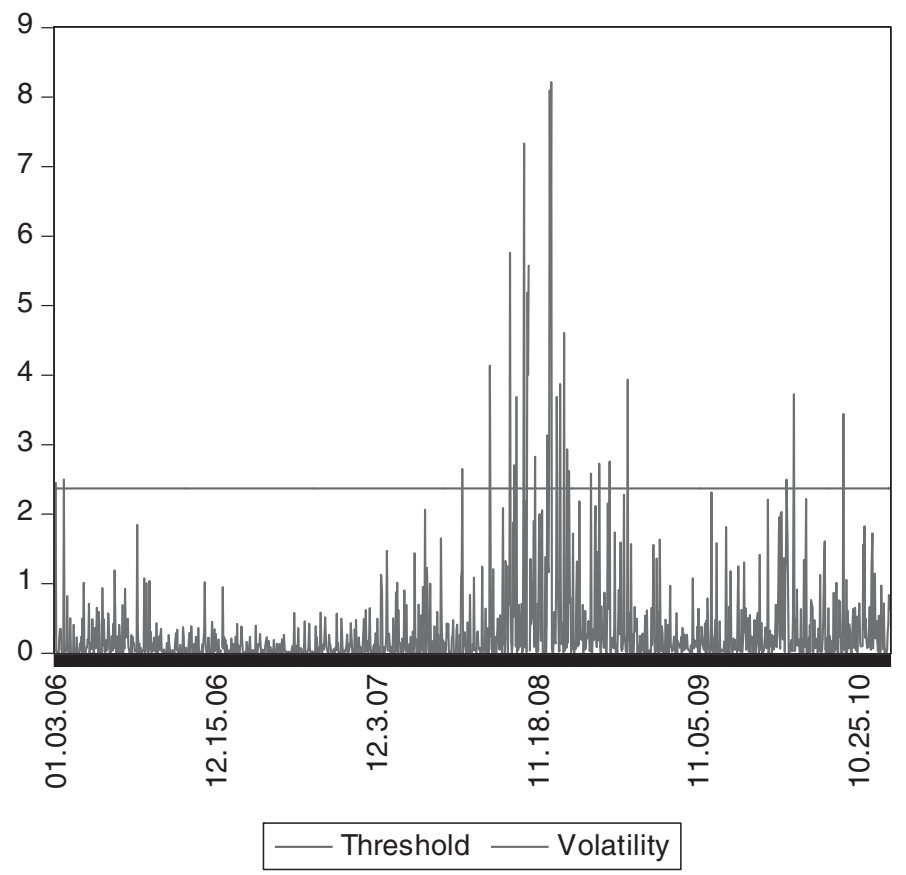

FIGURE 4. Euro-dollar volatility dynamics and threshold value. Threshold refers to the threshold value of volatility estimated by the STR model [Table 4, column (3)].

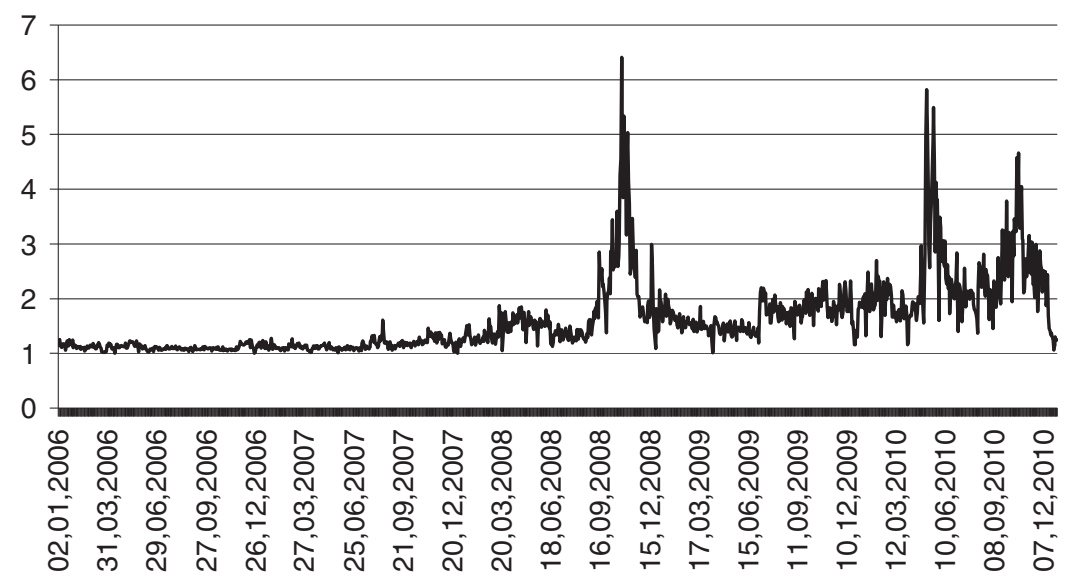

FIGURE 5. Impact of nonlinearity: the transition path dynamics. The impact of nonlinearity is computed from equation (5). 

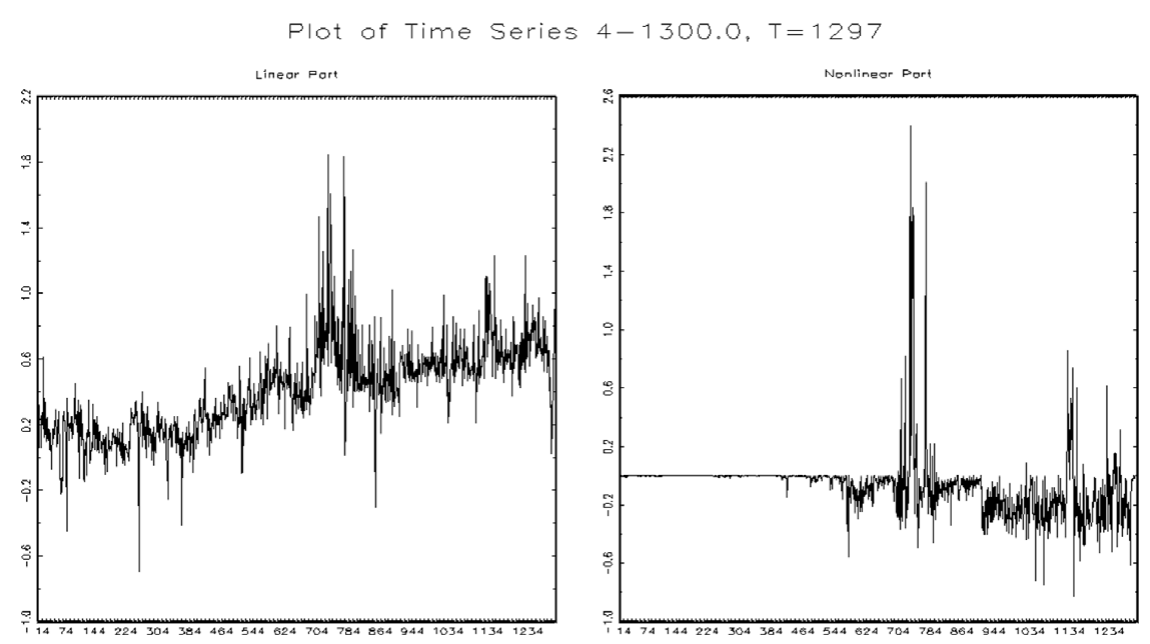

FIGURE 6. Linear and nonlinear parts of the LSTR1 model (euro-dollar). Values of the linear and nonlinear parts are plotted against time.

and trading volume and was really a period of pronounced crisis. In autumn 2008, the economic situation was gloomy in the wake of Black October. Volatility in the financial markets was very high and was influenced by news about the depth of the European recession, the magnitude of the leading indicators in the United States, ECB decisions regarding the interest rate, and rumors of stimulus plans.

Moreover, all traders want to go out of their positions during turbulent times, leading to a large volume (especially in the initial phases of a financial crisis, as in autumn 2008). According to Melvin and Taylor (2009), the surge in trading volume in 2008 was the consequence of a faster hot-potato process in response to increasing risk and of strong deleveraging effects. As a consequence, there is increased intensity of a news process, leading to both increased volume and increased volatility, and thus a stronger $\mathrm{MDH}$.

In contrast, the second period of nonlinearity (March to December 2010) seems to be less pronounced and of a different nature. In this stage, the trading volume was unnaturally high, but the level of spreads and volatility remained moderate. The surge in trading volume in the first subperiod (May to August 2010) was linked to a large depreciation of the euro exchange rate caused by the eruption of the sovereign debt crisis (mainly in Greece and Portugal). This period led to a wave of speculation against the euro, during which investors sold euros and bought dollars and yen. The second subperiod of nonlinearity (September 2010 to the end of December 2010) is characterized by a substantial appreciation in the euro-dollar exchange rate over the relevant period, combined with good Wall Street indices and good statistics regarding the U.S. economic cycle. Risk aversion increased and traders took high-risk positions to the benefit of the euro. The last part of the 
TABLE 5. Conditional ML estimates for the LSTR model (2)

\begin{tabular}{|c|c|c|c|c|c|}
\hline & \multirow{2}{*}{\multicolumn{2}{|c|}{$\begin{array}{l}\text { Euro-dollar } \\
2006-2012\end{array}$}} & \multicolumn{2}{|c|}{ Pound-dollar } & Euro-yen \\
\hline & & & \multicolumn{3}{|c|}{$2008-2010$} \\
\hline$s_{t}$ & $\begin{array}{c}\text { (1) } \\
\text { LSTR1 }^{21} \\
\text { volatility }_{t-1}\end{array}$ & $\begin{array}{c}(2) \\
\text { LSTR1 }^{2} \\
\text { volume }_{t-2}\end{array}$ & $\begin{array}{c}\text { (3) } \\
\text { LSTR1 } \\
\text { volume }_{t-1}\end{array}$ & $\begin{array}{c}\text { (4) } \\
\text { LSTR1 } \\
\text { volatility }_{t-1}\end{array}$ & $\begin{array}{c}(5) \\
\text { LSTR1 } \\
\text { volume }_{t-1}\end{array}$ \\
\hline \multicolumn{6}{|c|}{ Linear } \\
\hline Constant & $\begin{array}{l}-1.082^{* * *} \\
(-3.19)\end{array}$ & $\begin{array}{l}-2.720^{* * *} \\
(-4.55)\end{array}$ & $\begin{array}{l}-5.909^{* * *} \\
(-3.56)\end{array}$ & $\begin{array}{l}-6.059^{* * *} \\
(-4.42)\end{array}$ & $\begin{array}{c}-4.805^{*} \\
(1.82)\end{array}$ \\
\hline Volume & $\begin{array}{l}0.109^{* * * *} \\
(3.68)\end{array}$ & $\begin{array}{l}0.292^{* * *} \\
(3.46)\end{array}$ & $\begin{array}{l}0.399^{* * * *} \\
(6.17)\end{array}$ & $\begin{array}{l}0.527^{* * *} \\
(4.67)\end{array}$ & $\begin{array}{l}0.439^{* *} \\
(2.06)\end{array}$ \\
\hline \multicolumn{6}{|c|}{ Nonlinear } \\
\hline Constant & $\begin{array}{c}-6.914^{*} \\
(1.76)\end{array}$ & $\begin{array}{l}2.220^{* * *} \\
(2.82)\end{array}$ & $\begin{array}{l}-29.077^{\text {*** }} \\
(-3.28)\end{array}$ & $\begin{array}{c}-126.48^{* * *} \\
(-8.41)\end{array}$ & $\begin{array}{l}-37.855^{\text {*** }} \\
(-3.74)\end{array}$ \\
\hline Volume & $\begin{array}{l}0.701^{* *} \\
(2.23)\end{array}$ & $\begin{array}{l}0.380^{* * * *} \\
(2.74)\end{array}$ & $\begin{array}{l}2.319^{\text {*** }} \\
(3.27)\end{array}$ & $\begin{array}{l}10.322^{* * *} \\
(8.55)\end{array}$ & $\begin{array}{l}2.496^{* * *} \\
(3.76)\end{array}$ \\
\hline$\gamma / \hat{\sigma}_{s}$ & $\begin{array}{c}0.84 \\
(3.87)\end{array}$ & $\begin{array}{r}275.27 \\
(0.21)\end{array}$ & 73.43 & 14.04 & 1.07 \\
\hline$c_{1}$ & 3.01 & 12.09 & 12.48 & 2.76 & 12.77 \\
\hline$R^{2}$ & 0.11 & 0.14 & 0.17 & 0.30 & 0.10 \\
\hline
\end{tabular}

Note: $t$-stats are in parentheses.

sample is somewhat different from the rest because of optimistic expectations of economic recovery.

\subsection{Robustness Analysis}

Three kinds of robustness tests are conducted. First, we extend the sample period and once again estimate the STR model on the 2006-2012 period. Second, we use euro-yen and dollar-pound currency pairs to check our initial results. Third, we perform a GMM estimation on the euro-dollar currency pair.

In a first step, a longer data set concerning the euro-dollar currency pair is used: 2006-2012. The results (see Table 5) attest to the existence of a nonlinear MDH. However, the regressions using volatility as a transition variable are more relevant than results using the lagged volume as transition (for instance, the transition is less smooth than in previous estimates, and a two-lagged transition variable is needed). Thus the nonlinearity would be more related to switching between turbulent and calm periods than to the trading volume dynamics. Indeed, the nonlinear effect is the consequence of the heterogeneity of traders, which have a different price impact on volatility (more than the trading volume itself). Volatility as a transition variable is a somewhat better proxy of this fact. Finally, the magnitude of the coefficients 
is now smaller in the nonlinear part of the model than in our benchmark estimates using the 2006-2010 sample. The effects of the turbulence period (2008-2009) are probably weaker.

In a second step, we estimate our model using two other major currency pairs: euro-yen and dollar-pound. The results derived from the 2008-2010 sample, using volatility as a transition variable, are quite similar except for the euro-yen pair. The magnitude of the coefficients is slightly higher in the euro-yen market than in the dollar-pound market and (even more so) in the euro-dollar market. These divergences could be explained by the fact that liquidity levels are lower in euro-yen and dollar-pound markets.

In a third step, we estimate our STR model via instrumental variables using GMM. Indeed, one limitation of our analysis should be addressed. It might be supposed that our findings - an increase in mixture distribution in turbulent periods - could be biased if the trading volume were endogenous in times of crisis. In the theoretical analysis by Jeanne and Rose (2002), trading volume issuing from noise traders increasingly creates volatility as they progressively enter the market. But there is a feedback effect, because volatility acts as a benefit opportunity that attracts more traders into the market. There may thus be two-way causality between volume and volatility in turbulent times when the volume is high. To test this assumption, we implement Granger causality tests ${ }^{22}$ for the euro-dollar currency pair on different subsamples referring to the linear and nonlinear parts of the model, respectively. We find evidence of unidirectional causality from trading volume to volatility (and not the inverse) in the calm period (2006-autumn 2008). In contrast, during the more turbulent period (September 2008-January 2009), we cannot rule out the lack of bidirectional causality or the absence of an endogeneity issue.

Thus we again estimate our STR by GMM, in line with the very recent papers of Areosa et al. (2011) and Brueggemann and Riedel (2011). ${ }^{23}$ Lagged values of the regressors and spreads and of the squares of the spreads are used as instrumental variables. The $J$-test is performed to check the efficiency of these instruments. Table 6 reports the results. Although the magnitude of the coefficients is slightly lower than in the previous estimates, the results are qualitatively the same. To check the robustness of these estimates, we tried to change the set of instruments, the initial conditions, and the specification of the model, especially the lagged values of the endogenous variable. The qualitative properties of our results have remained consistent for all estimates.

\section{POLICY IMPLICATIONS OF A TOBIN TAX}

With regard to the effects of a Tobin tax on volatility, our results showed that a tax would be an effective instrument for reducing exchange rate volatility. In particular, a Tobin tax would have a higher marginal effect for reducing volatility when the Forex trading volume was abnormally high. Regarding the positive relationship between volatility and trading volume, the introduction of a Tobin tax would be 
TABLE 6. GMM estimates for LSTR model (2) concerning the euro-dollar currency pair with lagged volume as a transition variable (2008-2010)

\begin{tabular}{lccc}
\hline \multicolumn{2}{c}{ Linear part } & \multicolumn{2}{c}{ Nonlinear part } \\
\hline Constant & -2.289 & Constant & $-10.008^{* * *}$ \\
& $(-1.56)$ & & $(-4.98)$ \\
Volume & $0.211^{*}$ & Volume & $0.909^{* * *}$ \\
& $(1.77)$ & & $(37.9)$ \\
Volatility $_{t-1}$ & 0.086 & Volatility $_{t-1}$ & $-0.133^{* * *}$ \\
& $(1.55)$ & & $(-3.28)$ \\
Volatility $_{t-2}$ & -0.044 & Volatility $_{t-2}$ & $0.498^{* * *}$ \\
& $(-0.92)$ & & $(1240)$ \\
$\gamma$ & STR-GMM parameters & \\
$\gamma$ & 2.99 & $c_{1}$ & 12.39 \\
& \multicolumn{2}{c}{$p(J-$ Stat): 0.47} \\
\hline
\end{tabular}

Notes: Parentheses refer to $t$-stats for coefficients. Instruments used: constant, first four lagged values of the explanatory variables, spread $(-1)$ to $\operatorname{spread}(-4)$ and their squares.

effective in reducing volatility in normal times (as in the middle period of the sample), but it would be even more effective in turbulent periods, as in autumn 2008 and to a lesser extent in spring 2010. The tax would be a very valuable tool in times of high trading volume, with a surge in spreads and high volatility.

This result is in agreement with Tobin's writings (1974, 1978), which argue that the tax could reduce exchange rate volatility by discouraging destabilizing transactions, especially short-term transactions, more than long-term investments; indeed, the tax burden would be higher for short-term transactions. It may be supposed that if the tax proves to be more effective in reducing volatility in periods of turbulence, as indicated by our analysis, it is because it discourages transactions creating instability in times of crisis. Our results are thus in line with the studies by Frankel (1996), Westerhoff (2003), Ehrenstein et al. (2005), Westerhoff and Dieci (2006), and even Bloomfield et al. (2009).

However, a number of critical points need to be made regarding our study. In our reasoning, we assume that the markets considered (euro-dollar and euro-yen), and hence taxed, represent the aggregate foreign exchange market, without taking into account any fiscal evasion. This assumption is open to objection, on grounds similar to the criticism made by Hanke et al. (2010) of the study by Bloomfield et al. (2009), who consider only one independent taxed market.

Interestingly, our results clearly differ from those of the two previous empirical studies [Aliber et al. (2003) and Lanne and Vesala (2010)], which question the usefulness of a Tobin tax in reducing exchange rate volatility. Our results are, moreover, in conflict with studies that claim that a Tobin tax would be ineffective in reducing high levels of volatility: Bird and Rajan (1999, 2001), for example, 
find that the seminal model of Frankel (1996) is only valid if the ratio between the expected exchange rate and the spot rate is below 1.2 in the case of a tax rate of $1 \%$. However, during periods of speculative attacks, the decrease in the exchange rate exceeds $20 \%$ and then a tax would not sufficiently discourage speculators. Like Bird and Rajan, but in the context of interest rate arbitrage, Davidson (1997) shows that once the tax is unable to cover the full amount of potential gains or losses, it is necessarily ineffective. If speculators do not annualize the cost of the tax, then the rate of taxation stays well below the depreciation levels normally expected in a crisis situation. For speculators, depreciation therefore offers an opportunity for gain and to stay in the market and create volatility in spite of the tax.

Finally, our results seem to be incompatible with the two-tier tax rate proposed by Spahn (2002). This author proposed implementing an adjustable tax consisting of a low-rate tax in normal times, plus an exchange surcharge at prohibitive rates as a piggyback in turbulent times to discourage speculation significantly. Our results suggest that such a tax would be unnecessary, because the decreasing trading volume generated by the tax would have more effect on volatility in turbulent periods than in normal periods.

\section{CONCLUSION}

This paper examines the effect of trading volume on exchange rate volatility, i.e., the MDH, taking into account nonlinearity for the euro-dollar, pound-dollar, and euro-yen currency pairs. Using STR models, we find evidence that the relationship between trading volume and volatility tends to increase in turbulent periods when trading volume and volatility are at high levels. This is the first paper to evaluate the state dependency of the MDH. Our results are robust on different samples, currency pairs, and estimators.

Linking this finding to the Tobin tax debate implies that such a tax would be effective for reducing exchange rate volatility, even in turbulent periods. Our paper provides the first empirical corroboration of this proposition and seems to confirm some previous theoretical papers following Tobin concerning the effectiveness of such a measure. A Tobin tax would have been stabilizing and effective in the 2008 crisis when spreads, volume, and volatility were very high.

\section{NOTES}

1. See ECOFIN press notice 5555/13, 22 January 2013 and COM (2013) 71 Final, 14 February 2013. See also European Commission press notice IP/13/115, 14 February 2013 and the European Commission Website.

2. As shown by a recent survey [see McCulloch and Pacillo (2011)], the Tobin tax is an emotive issue.

3. Heterogeneous agent models [see the reviews by LeBaron (2006) and Hommes (2006)] help to solve the "exchange rate determination puzzle" [Bacchetta and Van Wincop (2003)], that is, the disconnection of the exchange rate from its underlying fundamentals most of the time and thus the emergence of excess volatility. 
4. These papers deal with securities transaction taxes, not only with the Tobin tax levied, especially on foreign exchange transactions.

5. See also Ehrenstein (2002).

6. Note, however, a recent contribution by Mougoué and Aggarwal (2011) that allows for nonlinearities by assessing the relationship between trading volume and volatility for three major currency futures contracts (the British pound, the Canadian dollar, and the Japanese yen). They carried out linear and nonlinear Granger causality tests to reveal strongly significant two-way nonlinear causality between return volatility and trading volume as a consequence of the heterogeneity of beliefs among traders regarding new information in foreign exchange markets. See also a recent paper by Jawadi and Ureche-Rangau (2013) that investigates the volume-volatility relationship for several developed and emerging stock markets in a nonlinear context.

7. To make comparisons, we also use the maximum value of the ask price and the minimum value of the bid price.

8. See Hartmann (1998a) for a survey of the available data set.

9. For the period from 1986 to 2006 , Schmidt (2008) arrived at an elasticity of -0.43 concerning the yen/U.S. dollar currency pair.

10. We conducted augmented Dickey-Fuller (ADF) and DF-GLS unit root tests and the stationarity KPSS test. Results of these tests are not reproduced here in order to save space, but are available upon request.

11. The Breusch-Godfrey LM test (with an AR(2) specification) is used here because the DurbinWatson test is not valid if there are lagged values of the dependent variable on the right-hand side of the estimated equation.

12. We conduct robustness checks using a three-simultaneous-equations model with the following third equation: $\ln (\text { volatility })_{t}=\beta_{9}+\beta_{10} \ln (\text { spread })_{t}+\beta_{11} \ln (\text { volume })_{t}+\varepsilon_{3 t}$. However, this third equation has limited explanatory power.

13. See also Hartmann $(1998,1999)$ for single-equation estimates of spreads and trading volume.

14. As underlined by Wooldridge (2010), the most important weakness of 3SLS estimators is that, if one equation in the system is misspecified, all parameters estimates become inconsistent because parameters are estimated for the whole system and not for each equation. To check the specification of our system, we first refer to the literature [Demos and Goodhart (1996) for instance] and second, we compute for comparison purposes traditional 2SLS and 3SLS methods (available upon request). Because the parameter estimates are very similar in both estimations, we can conclude that the simultaneous equations model is correctly specified.

15. See for instance Melvin and Yin (2000) and Bauwens et al. (2006) for empirical studies concerning the Forex.

16. Spread is also a good proxy of turbulence periods. Using lagged spreads instead of lagged volatility leads to very similar results.

17. We also carried out rolling regressions in a preliminary version of this paper.

18. See Hansen (1996) for a detailed discussion of this issue.

19. All the results are available upon request.

20. The Newton-Raphson algorithm can also be used.

21. Lagged coefficients are not reported, in order to save space, but are available upon request.

22. Results are not provided, in order to save space, but are available upon request.

23. Our GMM code was programmed on the basis of the Ox code from Brueggemann and Riedel (2011).

\section{REFERENCES}

Aliber, R., B. Chowdhry, and S. Yan (2003) Some evidence that a tax on foreign exchange transactions may increase volatility. European Finance Review 7, 481-510.

Areosa, W.D., M. McAleer, and M.C. Medeiros (2011) Moment-based estimation of smooth transition regression models with endogenous variables. Journal of Econometrics 165, 100-111. 
Bacchetta, P. and E. Van Wincoop (2003) Can Information Heterogeneity Explain the Exchange Rate Determination Puzzle? NBER working paper 9498.

Bacon, D.W. and D.G. Watts (1971) Estimating the transition between two intersecting straight lines. Biometrika 58, 525-534.

Bauwens, L., D. Rime, and G. Sucarrat (2006) Exchange rate volatility and the mixture of distribution hypothesis. Empirical Economics 30, 889-911.

Bianconi, G., T. Galla, M. Marsili, and P. Pin (2009) Effects of Tobin taxes in minority game markets. Journal of Economic Behaviour and Organization 70(1-2), 231-240.

Bird, G. and R.S. Rajan (1999) Would International Currency Taxation Help Stabilise Exchange Rates and Avoid Currency Crises in Developing Countries? Centre for International Economic Studies (CIES), University of Adelaide, CIES Discussion Paper No. 99/11.

Bird, G. and R.S. Rajan (2001) International currency taxation and currency stabilisation in developing countries. Journal of Development Studies 37(3), 21-38.

BIS (Bank for International Settlements) (2010) Triennal Central Bank Survey of Foreign Exchange and Derivatives Market Activity in April 2010. Preliminary Global Results. Basel, Switzerland.

Bismans, F. and O. Damette (2008) Currency transaction tax elasticity: An econometric estimation. International Economics 3, 193-212.

Bloomfield, R., M. OHara, and G. Saar (2009) How noise trading affects markets: An experimental analysis. Review of Financial Studies 22, 2275-2302.

Brueggemann, R. and J. Riedel (2011) Nonlinear interest rate reaction functions for the UK. Economic Modelling, 28, 1174-1185.

Davidson, P. (1997) Are grains of sand in the wheels of international finance sufficient to do the job when boulders are often required? Economic Journal 107(442), 671-686.

Demos, A. and C.A. Goodhart (1996) The interaction between the frequency of market quotations, spreads and volatility in the foreign exchange market. Applied Economics 28, 377386.

Ehrenstein, G. (2002) Cont-Bouchaud percolation model including Tobin tax. International Journal of Modern Physics 13, 1323-1331.

Ehrenstein, G., F. Westerhoff, and D. Stauffer (2005) Tobin tax and market depth. Quantitative Finance 5(2), 213-218.

Eichengreen, B., J. Tobin, and C. Wyplosz (1995) Two cases for sand in the wheels of international finance. Economic Journal 105(428), 162-172.

Frankel, J.A. (1996) How well do foreign exchange markets function: Might a Tobin tax help? InI. Grunberg, M. Ul Haq, and I. Kaul (eds.), The Tobin Tax: Coping with Financial Volatility, pp. 41-81. Oxford, UK: Oxford University Press.

Franses, P.H. and D. Van Dijk (2000) Non-Linear Time Series Models in Empirical Finance. Cambridge, UK: Cambridge University Press.

Friedman, M. (1953) The case of flexible exchange rates. In Essays in Positive Economics. Chicago: University of Chicago Press.

Galati, G. (2000) Trading Volumes, Volatility and Spreads in Foreign Exchange Markets: Evidence from Emerging Market Countries. BIS working paper 93, pp. 1-33.

Haberer, M. (2004) Might a Securities Transactions Tax Mitigate Excess Volatility? Some Evidence from the Literature. Discussion paper 04/06, University of Konstanz.

Hanke, M., J. Huber, M. Kirchler, and M. Sutter (2010) The economic consequences of a Tobin tax: An experimental analysis. Journal of Economic Behavior and Organization 74(1-2), 5871.

Hansen, B.E. (1996) Inference when a nuisance parameter is not identified under the null hypothesis. Econometrica 64, 413-430.

Hartmann, P. (1998a) Currency Competition and Foreign Exchange Markets: The Dollar, the Yen and the Euro. Cambridge, UK: Cambridge University Press.

Hartmann, P. (1998b) Do Reuters spreads reflect currencies differences in global trading activity? Journal of International Money and Finance 17(5), 757-785. 
Hartmann, P. (1999) Trading volumes and transaction costs in the foreign market evidence from daily dollar-yen spot data. Journal of Banking and Finance 23(5), 801-824.

Hommes, C.H. (2006) Heterogeneous agent models in economics and finance. In L. Tesfatsion and K.L. Judd (eds.), Agent-based Computational Economics (Handbook of Computational Economics, Vol. 2), Chap. 23, pp. 1109-1186. Amsterdam: Elsevier Science.

Jawadi, F. and L. Ureche-Rangau (2013) Threshold linkages between volatility and trading volume: Evidence from developed and emerging markets. Studies in Nonlinear Dynamics and Econometrics 17(3), 313-333.

Jeanne, O. and A. Rose (2002) Noise trading and exchange rate regimes. Quarterly Journal of Economics. 117(2), 537-569.

Keynes, J.M. (1936) The General Theory of Employment, Interest and Money. London: Macmillan.

Lanne, M. and T. Vesala (2010) The effect of a transaction tax on exchange rate volatility. International Journal of Finance and Economics 15(2), 123-133.

LeBaron, B. (2006) Agent-based computational finance. In L. Tesfatsion and K.L. Judd (eds.), Agentbased Computational Economics (Handbook of Computational Economics, Vol. 2), Chap. 24, pp. 1187-1232. Amsterdam: Elsevier Science.

Mannaro, K., M. Marchesi, and A. Setzu (2008) Using an artificial market for assessing the impact of Tobin-like transaction taxes. Journal of Economic Behavior and Organization 67 445462.

McCulloch, M. and G. Pacillo (2011) The Tobin Tax: A Review of the Evidence. Institute of Development Studies research paper 68, pp. 1-77.

Melvin, M. and M.P. Taylor (2009) The crisis in the foreign exchange market. Journal of International Money and Finance 28(8), 1317-1330.

Melvin, M. and X. Yin (2000) Public information arrival, exchange rate volatility and quote frequency. Economic Journal 110, 644-661.

Mende, A. and L. Menkhoff (2003) Tobin tax effects seen from the foreign exchange markets microstructure. International Finance 6, 227-247.

Mougoué, M. and R. Aggarwal (2011) Trading volume and exchange rate volatility: Evidence for the sequential arrival of information hypothesis. Journal of Banking and Finance 35(10), 2690-2703.

Palley, T.I. (1999) Speculation and Tobin taxes: Why sand in the wheels can increase economic efficiency. Journal of Economics 69(2), 113-126.

Pellizzari, P. and F. Westerhoff (2009) Some effects of transaction taxes under different microstructures. Journal of Economic Behavior and Organization 72, 850-863.

Phillips, P.C.B. (1986) Understanding spurious regressions in econometrics. Journal of Econometrics $33,311-340$.

Schmidt, R. (2008) The Currency Transaction Tax: Rate and Revenues Estimates. Tokyo: United Nations University Press.

Shi, K. and J. Xu (2009) Entry cost, the Tobin tax, and noise trading in the foreign exchange market. Canadian Journal of Economics 42(4), 1501-1526.

Spahn, P.B. (2002) On the Feasibility of A Tax on Foreign Exchange Transactions. Federal Ministry for Economic Cooperation and Development, Bonn, Germany.

Teräsvirta, T. (1994) Specification, estimation and evaluation of smooth transition autoregressive models. Journal of the American Statistical Association 89, 208-210.

Teräsvirta, T. (1998) Modeling relationships with smooth transition regressions. In A. Ullah and D.E. Giles (eds.), Handbook of Applied Economic Statistics, pp. 507-552. New York: Dekker.

Teräsvirta, T. (2004) Smooth transition regressions modeling. In H. Lutkepohl and M. Kratzig (eds.), Applied Time Series Econometrics, pp. 222-242. Cambridge, UK: Cambridge University Press.

Tobin, J. (1974) The New Economics One Decade Older: The Elliot Janeway Lectures in Honor of Joseph Schumpeter. Princeton, NJ: Princeton University Press.

Tobin, J. (1978) A proposal for international monetary reform. Eastern Economic Journal 3(3-4), $153-159$.

Tobin, J. (1984) On the efficiency of the financial system. Lloyds Bank Review 153(July), 261-286. 


\section{2}

Tobin, J. (1996) Prologue. In I. Grunberg, M. Ul Haq, and I. Kaul (eds.), The Tobin Tax: Coping with Financial Volatility, pp. 9-18. Oxford, UK: Oxford University Press.

Van Dijk, D., T. Teräsvirta, and P.H. Franses (2002) Smooth transition autoregressive models. A survey of recent developments. Econometric Reviews 21, 1-47.

Werner, I.M. (2003) Comment on "Some Evidence That a Tobin Tax on Foreign Exchange Transactions May Increase Volatility." European Finance Review 7, 511-514.

Westerhoff, F. (2003) Heterogeneous traders and the Tobin tax. Journal of Evolutionary Economics 13, 53-70.

Westerhoff, F. and R. Dieci (2006) The effectiveness of Keynes-Tobin transaction taxes when heterogeneous agents can trade in different markets: A behavioural finance approach. Journal of Economic Dynamics and Control 30(2), 293-322.

Wooldridge, J. (2010) Econometric Analysis of Cross Section and Panel Data, 2nd ed. Cambridge, MA: MIT Press.

Zellner, A. and H. Theil (1962) Three-stage least squares: Simultaneous estimation of simultaneous equations. Econometrica 30, 54-78. 